\title{
Editorial comment on: Analysis of the İstanbul Forensic Medicine Institute expert decisions on recurrent laryngeal nerve injuries due to thyroidectomy between 2008-2012
}

\author{
Mehmet Hacıyanlı, Erdinç Kamer, Emine Özlem Gür
}

Cite this paper as: Haciyanlı M, Kamer E, Gür EÖ. Editorial comment on: Analysis of the İstanbul Forensic Medicine Institute expert decisions on recurrent laryngeal nerve injuries due to thyroidectomy between 2008-2012. Turk J Surg 2017; 33(1): 47-48.

Clinic of General Surgery, Katip Çelebi University İmir Atatürk Training and Research Hospital, İzmir, Turkey

Address for Correspondence Erdinç Kamer e-mail: erdinc.kamer@gmail.com

Received: 09.02.2017

Accepted: 16.02.2017

(C) Copyright 2017 by Turkish Surgical Association

Available online at

www.turkjsurg.com
Dear Editor,

We read with great interest the study entitled "Analysis of the İstanbul Forensic Medicine Institute expert decisions on recurrent laryngeal nerve injuries due to thyroidectomy between 2008-2012 "by Karakaya et al. (1).The authors retrospectively evaluated the approach on recurrent laryngeal nerve (RLN) injuries as well as parameters taken into consideration in differentiating complication and malpractice.

According to the article, the institution consideredunilateral nerve injuries as a complication if the indication for thyroidectomy and postoperative follow-up were proper, regardless of surgical technique. However, if the injury was bilateral then the surgical technique was also evaluated. The study reported that there were no inadequacies in operation indications, type of thyroidectomy and postoperative follow-up in any of the cases in the study, and that all 19 unilateral nerve injurieshave been considered as complications. On the other hand, all 19 cases with bilateral nerve injuries were reported to have been considered as malpractice since any situation that may prevent or complicate nerve dissection was not stated in pre-operative imaging reports, operative notes, or pathology reports.

One of the criteria taken into consideration for discriminating malpractice from complication inrecurrent laryngeal nerve injurieswasthe lack of evidence on any signs that will make nerve dissection difficult, but this alone is not a sufficient criterion. We would like to emphasize the need for comprehensive evaluation parameters todefinemalpractice.

It should be standard practice to identify the integrity of the RLN visually in thyroid surgery and to state so in the operative note. Although RLN injury can be caused by mechanisms such as shearing, rupture, suturing, and thermal damage, retraction injury is also an important cause. Intraoperative neuro-monitoring (IONM) experiences have shown that visualization of an intact nerve at the time of operation does not mean that it is functionally intact (2). Temporary or permanent vocal cord paralysis may be encountered even when the nerve is visually identifiable, preserved throughout its course, and the utmost care is given during dissection.

Bilateral vocal cord paralysis may also occur due to over-inflation or traumatic withdrawal of the intubation tube (3).

Another issue that is noteworthy in the study is that although none of the patients underwent preoperative vocal cord (VC) inspection, all files have been evaluated as if all the VCs were normal before surgery. One conclusion to be drawn from this is the necessity of a VC evaluation before thyroidectomy, especially prior to secondary interventions.

We also think that, in the evaluation of these types of files, there is a need for a data system documenting the individual complication rates of surgeons on this type of surgery.

The authors stated in the discussion section that the injury "may have been missed due to not dissecting the nerve through its entire tract" and recommended in the conclusion section that "continuing the operation on the other side only after assuring that the nerve has not been damaged on one side by careful dissection may prevent surgeons from legal problems". 
Although there are advocates that careful dissection does not increase nerve damage, currently many authors suggest that RLN is very susceptible to surgical dissection and that minimal dissection should be performed since dissection throughout its tract will put the nerve at greater risk $(4,5)$. Since the issue is controversial, identification of the nerve, not its dissection, should be emphasized to preclude RLN injury.

Although it is still controversial if intraoperative neuro-monitoring leads to a reduction in RLN injury, its most important contribution is providing the prognostic information on functional integrity of a visually intact nerve. Thus, it may be possible to avoid bilateral VC paralysis, and the test can offer medico-legal assurance by providingquantitative and documentable information. However, the use of IONM in thyroid surgery is not standard practice and cost-effectiveness is still an important issue.

We believe that since RLN injuries constitute a substantial part of general surgery-related case files and due to difficulties in decision-making, more objective criteria that will form the basis for evaluation of such filesshould be introduced.

Peer-review: Externally peer-reviewed.

Author Contributions: Concept - M.H., E.K.; Design - M.H., E.K.; Supervision - M.H.; Resource - M.H., E.Ö.G.; Materials - M.H.; Data Collection and/orProcessing - M.H., E.K.; Analysis and/or Interpretation - M.H.;
Literature Search - M.H., E.K, E.Ö.G.; Writing Manuscript - M.H.; Critical Reviews - M.H., E.K.

Conflict of Interest: No conflict of interest was declared by the authors.

Financial Disclosure: The authors declared that this study has received no financial support.

\section{REFERENCES}

1. Karakaya MA, Koç $O$, Ekiz F, Ağaçhan AF, Göret NE.Analysis of the Istanbul Forensic Medicine Institute expert decisions on recurrent laryngeal nerve injuries due to thyroidectomy between 2008-2012. Ulus Cerrahi Derg 2016; 32: 43-46. [CrossRef]

2. Schneider R, Randolph G, Dionigi G, Barczyński M, Chiang FY, Triponez $\mathrm{F}$, et al. Prospectivestudy of vocal fold function after loss of the neuromonitoring signal in thyroid surgery: The International Neural Monitoring Study Group's POLT study. Laryngoscope 2016; 126: 1260-1266. [CrossRef]

3. Kikura M, Suzuki K, Itagaki T, Takada T, Sato S. Age and comorbidity as risk factors for vocal cord paralysis associated with tracheal intubation. Br J Anaesth 2007; 98: 524-530. [CrossRef]

4. Chiang FY, Lu IC, Tsai CJ, Hsiao PJ, Hsu CC, Wu CW. Does extensive dissection of recurrent laryngeal nevre during thyroid operation increase the risk of nevre injury? Evidence from the application of intraoperative neuromonitoring. Am J Otolaryngol 2011; 32: 499-503. [CrossRef]

5. Reeve T, Thompson NW. Complications of thyroid surgery: how to avoid them, how to manage them, and observations on their possible effect on the whole patient. World J Surg 2000; 24: 971-975.[CrossRef] 